\title{
Sensory and Microbial Evaluation of Microwave treated Sugarcane Juice
}

\author{
Neha Pradhan ${ }^{1 *}$, Dilip Kumar², Priyanka Singh ${ }^{2}$ and P. S. Pisalkar ${ }^{1}$ \\ ${ }^{1}$ Department of Agricultural Processing and Food Engineering, Indira Gandhi \\ Krishi Vishwa vidyalaya, Raipur (C.G.), India \\ ${ }^{2}$ Department of Agricultural Engineering, ICAR-Indian Institute of Sugarcane Research, \\ Lucknow (U.P.), India \\ *Corresponding author
}

\section{A B S T R A C T}

\begin{tabular}{l} 
K e y w o r d s \\
$\begin{array}{l}\text { Sugarcane juice, } \\
\text { microwave, } \\
\text { sensory, } \\
\text { microbiological } \\
\text { analysis. }\end{array}$ \\
\hline Article Info \\
\hline $\begin{array}{l}\text { Accepted: } \\
\text { 05 February } 2020 \\
\text { Available Online: } \\
\text { 10 March } 2020\end{array}$ \\
\hline
\end{tabular}

A study has been undertaken at ICAR-Indian Institute of Sugarcane Research, Lucknow with an objective to study the sensory and microbial properties of microwave treated sugarcane juice under ambient and refrigerated conditions. Peeled sugarcane sticks were subjected to heat treatment at 10 psi for 5 minutes then sticks was immediately cooled in a deep freezer and juice was extracted through sugarcane juice extractor followed by the addition of lemon juice to maintain the $\mathrm{pH}$ 4.2-4.3. After this the juice was subjected to microwave treatments for time period of 1-4 minutes. All the treated juices were bottled and pasteurized in hot water at $80^{\circ} \mathrm{C}$ for 25 minutes. All the lots were stored under ambient and refrigerated condition. The prepared juices were observed for sensory (appearance, flavour and overall acceptability) and microbiological attributes (total plate count and yeast and mold count). The results revealed that a good quality beverage from sugarcane juice with satisfactory storage stability of 21 days at ambient condition and 56 days at refrigerated condition could be prepared when the juice was treated with microwave for a time a period 3 minutes.

\section{Introduction}

In India sugarcane is generally crushed to obtain juice which serves as a thirst quenching drink in hot summers. Sugarcane juice is great for recharging energy because it is rich in carbohydrate and iron. Being a nutritious product containing natural sugars, minerals and organic acids, sugarcane juice has many medicinal properties. It strengthens the stomach, kidneys, heart, eyes and brain. The juice is beneficial in fevers. Sugarcane juice is very useful in scanty urination.

For better results, it should be mixed with lime juice, ginger juice and coconut water. Mixed with lime juice, it can hasten recovery from jaundice. Sugarcane juice is a fattening food. It is thus an effective remedy for thinness. Rapid gain in weight can be 
achieved by its regular use (Karthikey and Samipillai, 2010). Development of effective treatments or procedures to keep the fresh quality of sugarcane juice would allow it to be more widely marketed, and would enhance its quality and safety as well.

Considerable efforts have been aimed at stabilizing the juice quality during processing and distribution. The most widely used method for delaying deterioration is blanching before juice extraction (Margherita and Giussani, 2003) and addition of antioxidant agents (Ozogluand Bayindirli, 2002). Blanching treatment is usually performed by exposing vegetables or fruits to hot or boiling water for several seconds or minutes (Kidmose and Martens, 1999; Margherita and Giussani, 2003). The most widespread antioxidant and acidifying agent used in juice processing is ascorbic acid (Choi et al., 2002).

A Novel food processing technology for microbial inactivation in food products extends their shelf life and enables the retention of their nutritional and sensory attributes. It includes High hydrostatic pressure (HHP), Pulsed electric fields (PEF), Gamma radiation (Mohd et al., 2007) and Microwave. In this study, Microwave is used to increase the shelf life of sugarcane juice. Microwave energy can also be used in food applications because of its heating properties. When microwaves are reflected or passed from a material, the energy is absorbed by water molecules including the food constituents.

Similarly, when microwaves are passed through sugarcane juice, water molecules and other polar molecules absorb the energy and tend to align themselves in a specific direction with respect to the electric field. The molecules start oscillating at frequencies of $2.45 \mathrm{GHz}$ to generate intermolecular friction which ultimately heats the juice.
The present study was aimed to see the effect of microwave on the microbial and sensory properties of the sugarcane juice and also its effect on the shelf-life of sugarcane juice.

\section{Materials and Methods}

\section{Source of material}

The fully matured sugarcane sticks of variety CoLk94184 were harvested from the farms of ICAR-Indian Institute of Sugarcane Research, Lucknow (U.P.).

\section{Pre-treatment and extraction of sugarcane juice}

The sugarcane sticks were washed, graded, deeply peeled and scrubbed with the help of peeler. Then sugarcane stems were steam treated in autoclave ( 5 minutes at $10 \mathrm{psi}$ ). The stems were then kept in deep freezer for the immediate cooling. After cooling juice was extracted using the sugarcane juice extraction machine and filtered through muslin cloth to remove the extraneous matter. The extracted juice was then immediately placed in deep freezer to prevent any further change in juice colour.

\section{Selection of treatments}

Different lots of sugarcane juice were subjected to the following time intervals of microwave treatments during processing: $\mathrm{T} 1=1 \mathrm{~min}, \mathrm{~T} 2=2 \mathrm{~min}, \mathrm{~T} 3=3 \mathrm{~min}$ and $\mathrm{T} 4=4$ min. In all the treatments (T1, T2, T3 and T4) juice was filled in sterilized glass bottles and bottles were tightly capped by manual bottle capping machine, and after that heat treatment ( $80^{\circ} \mathrm{C}$ for 25 minutes) was given in the hot water bath. Thereafter, bottles were kept in refrigerator. The samples were drawn and analysed periodically for sensory and microbiological evaluationat an interval of 7 days under ambient and refrigerated conditions. 


\section{Results and Discussion}

Effect of microwave on sensory parameters of sugarcane juice

Sensory evaluation regarding appearance, flavour and overall acceptability were carried out for both at ambient and refrigerated conditions. The decrease in the appearance score is due to the increasing PPO activity that causes browning due to which the juice becomes darker.

\section{Appearance}

TheFig. 1 and 2 clearly indicated that the appearance scores decreased significantly in all the treatments during storage period under ambient as well as refrigerated conditions respectively. Similar result was reported by Mao et al., (2007).However, the minimum decrease was observed in $\mathrm{T} 3$.

\section{Flavour}

The Figures 3 and 4 clearly indicated that the appearance scores decreased significantly in all the treatments during storage period under ambient as well as refrigerated conditions. Similar, result found by Mao et al., (2007) during the study on preservation of sugarcane juice. The best results were observed in T3

\section{Overall acceptability}

The initial overall acceptability score for all treated juice in Fig 5 and 6 was ranged from 8.0 to 8.5 in 0 days, after that the scores declined significantly during storage under ambient and refrigerated conditions owing to oxidative and enzymatic reactions. These findings were accordance with Chauhan et al., 2002 and Singh etal. (2014).

\section{Effect of microwave on microbial properties of sugarcane juice}

\section{Total plate count}

From the results of the present study as presented in the Fig 7 it was observed that total plate count was increased in all the treatments during storage under ambient as well as refrigerated conditions. Under ambient conditions, the bacterial growth increased up to 21 days of storage with the minimum increase in T3 $(1.5 \mathrm{cfu} / \mathrm{ml})$. Under refrigerated conditions, total plate count values increased up to 56 days of storage with minimum in T3 $(2.2 \mathrm{cfu} / \mathrm{ml})$. Similar trend was observed under ambient condition but the growth was higher than refrigerated condition since refrigerated condition retarded the growth of micro-organism. Chauhan et al., (2002) also reported similar microbial changes in pasteurized stored sugarcane juice.

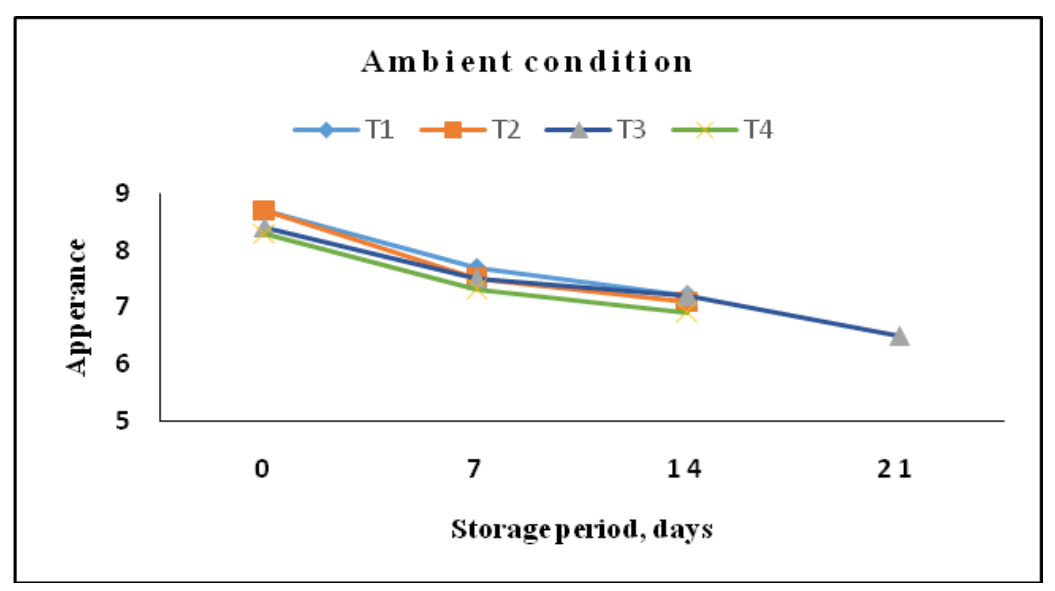

Fig.1 Effect of treatments on appearance of sugarcane juice stored under ambient condition 


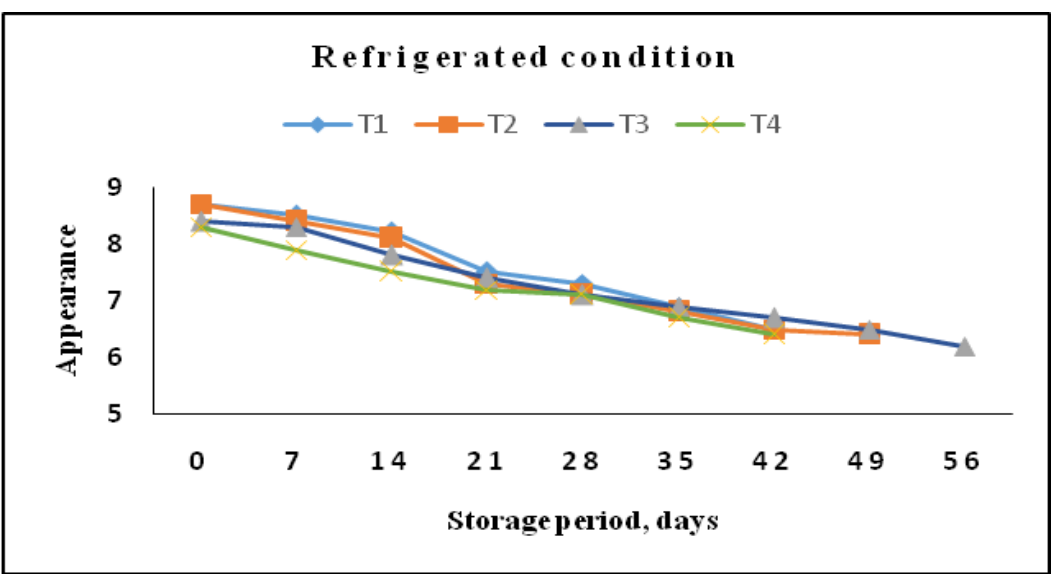

Fig.2 Effect of treatments on appearance of sugarcane juice stored under refrigerated condition

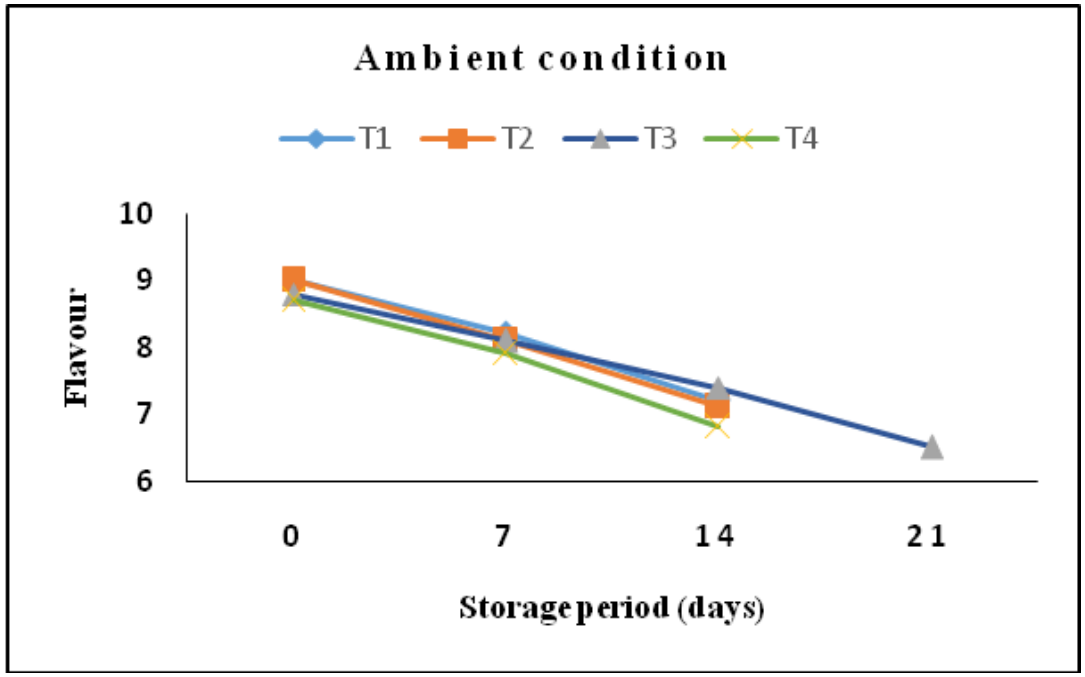

Fig.3 Effect of treatments on flavour of sugarcane juice stored under ambient condition

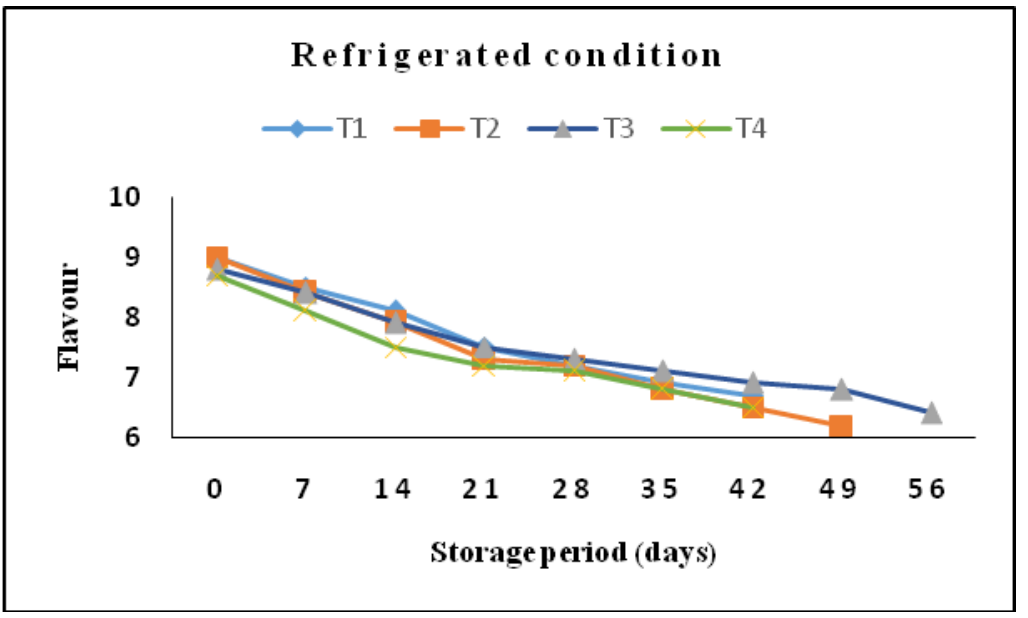

Fig.4 Effect of treatments on flavour of sugarcane juice stored under refrigerated condition 


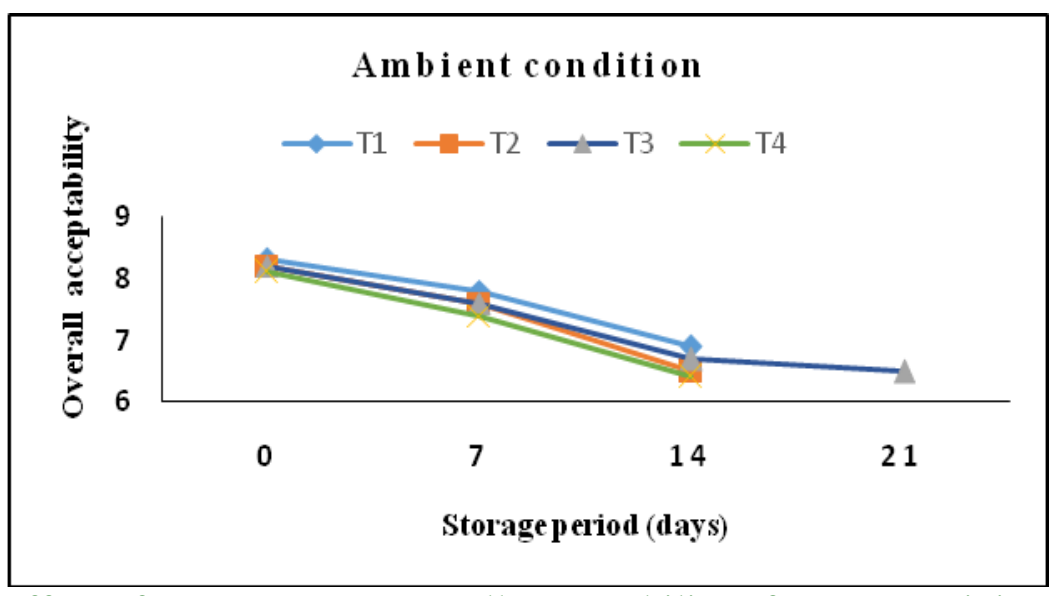

Fig.5 Effect of treatments on overall acceptability of sugarcane juice stored under ambient condition

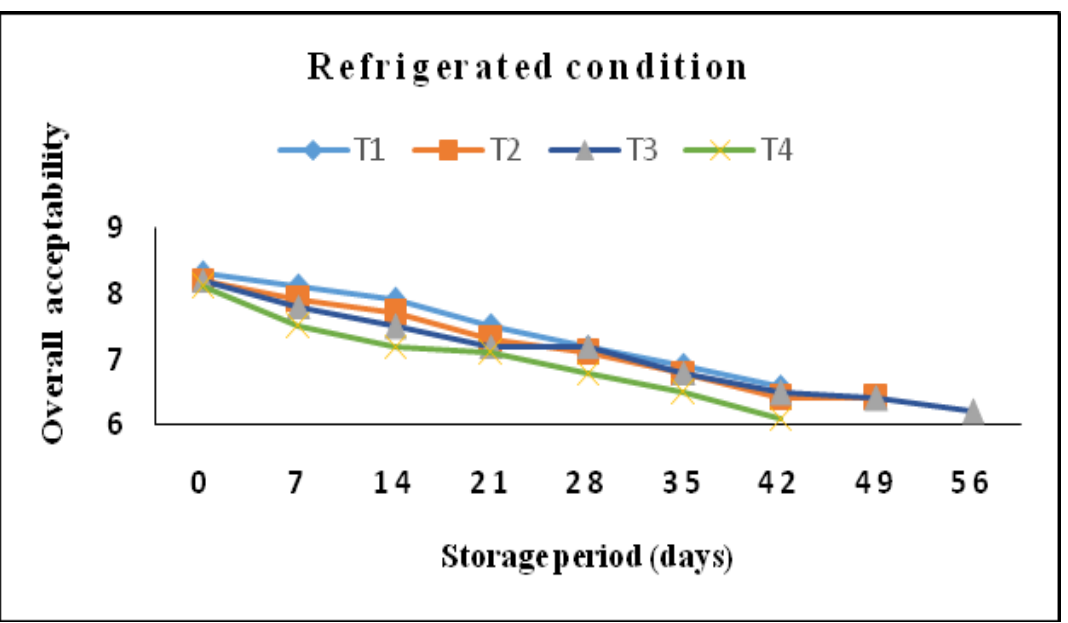

Fig.6 Effect of treatments on overall acceptability of sugarcane juice stored under refrigerated condition

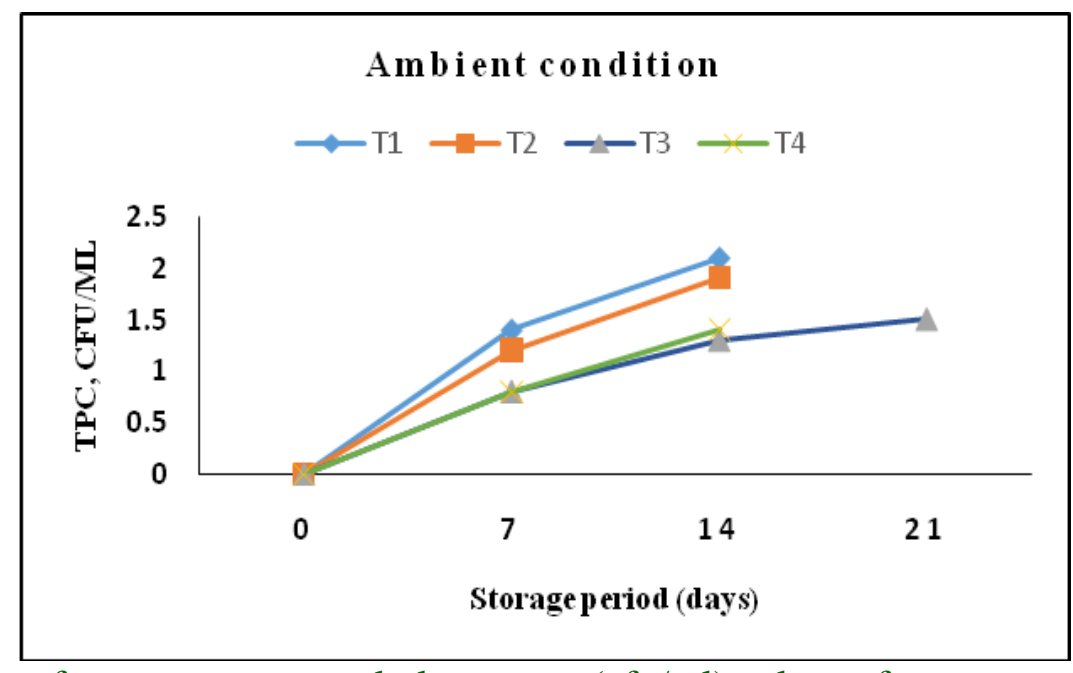

Fig,7 Effect of treatments on total plate count $(\mathrm{cfu} / \mathrm{ml})$ values of sugarcane juice stored under ambient condition 


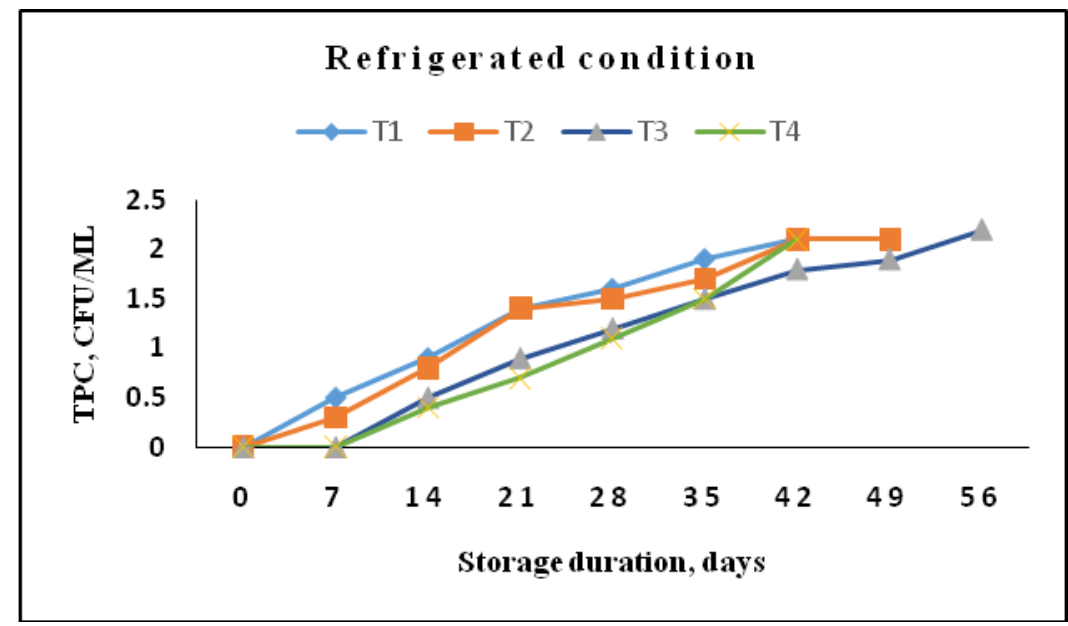

Fig.8 Effect of treatments on total plate count $(\mathrm{cfu} / \mathrm{ml})$ values of sugarcane juice stored under refrigerated condition

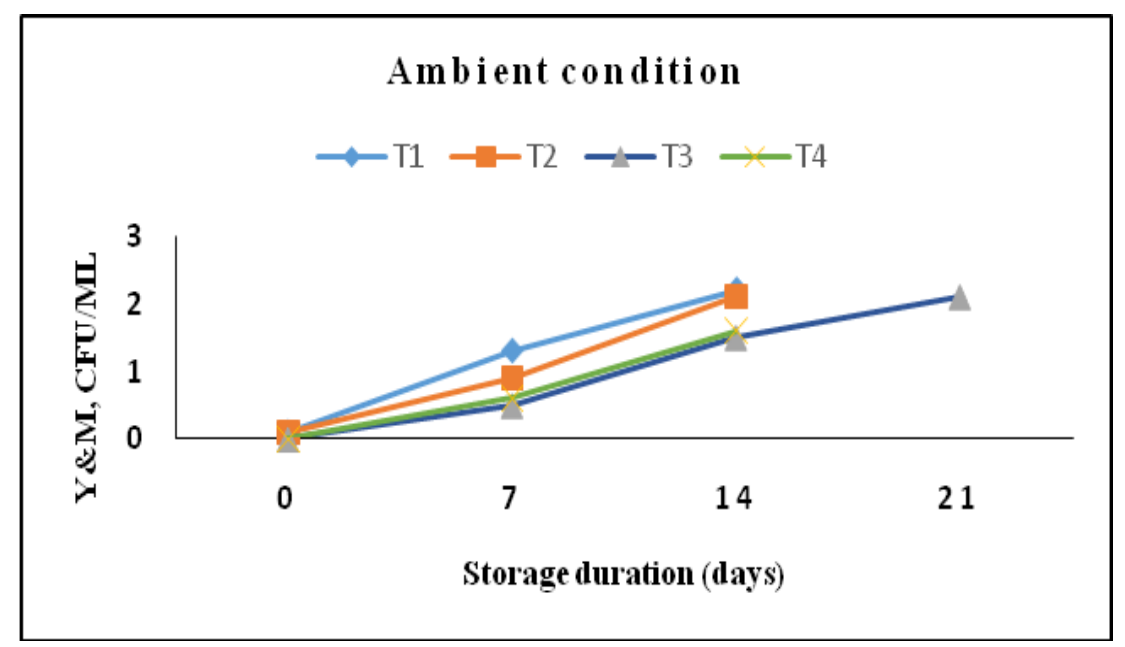

Fig.9 Effect of treatments on yeast and mould count $(\mathrm{cfu} / \mathrm{ml})$ of sugarcane juice stored under ambient condition

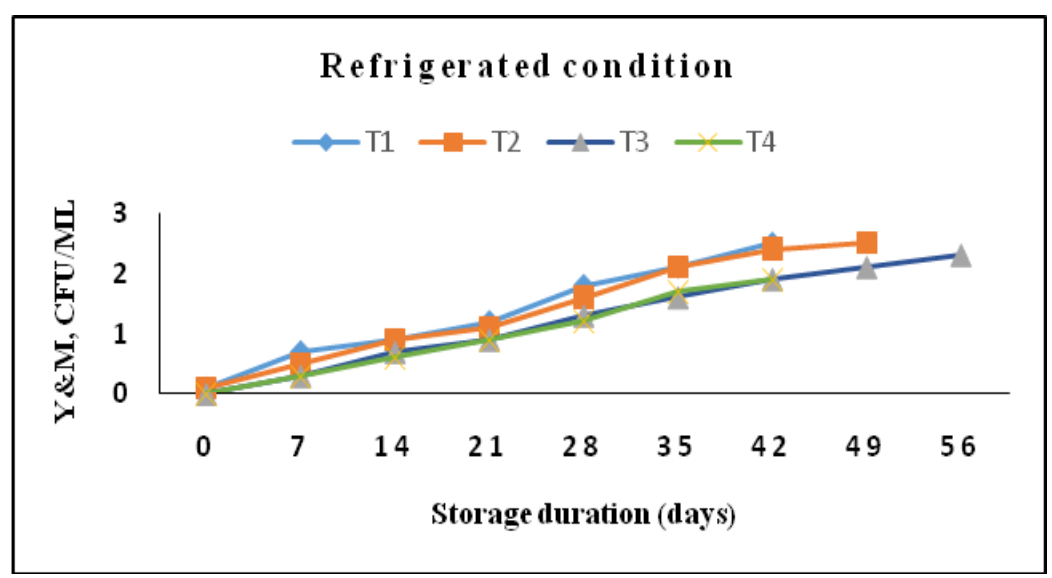

Fig.10 Effect of treatments on yeast and mould count $(\mathrm{cfu} / \mathrm{ml})$ of sugarcane juice stored under refrigerated condition 


\section{Yeast and mould count}

From the results of the present study as presented in the Fig.9 and 10it was observed that yeast and mouldcount was increased in all the treatments during storage period under ambient as well as refrigerated conditions.

Under ambient conditions, the bacterial growth increases up to 21 days of storage with the minimum increase in $\mathrm{T} 3(2.1 \mathrm{cfu} / \mathrm{ml})$. Under refrigerated conditions, yeast and mould count values increased up to 56 days of storage with minimum increase in $\mathrm{T} 3$ $(2.3 \mathrm{cfu} / \mathrm{ml})$.

The increase in microbial load was less in refrigerated condition than under ambient condition since low temperature inhibits the growth of microorganism. Chauhan et al., (2002) also reported similar microbial changes in pasteurized stored sugarcane juice.

It can be concluded from the present investigation that good quality beverage from sugarcane juice of variety CoLk 94184 with satisfactory storage stability of 56 days at refrigeration could be achieved by the use of microwave treatment without adding preservatives.

At the end of storage studies T3 was the best for retaining the various sensory and microbiological properties. The time period of 3 minutes of microwave treatment in the juice enhanced the storage of juice for 21 days of storage under ambient conditions and 56 days of storage under refrigerated conditions.

\section{References}

Chauhan O. P., Singh D., Tyagi S. M., and Balyan D. K. (2002). Studies on Preservation of Sugarcane Juice. International Journal of Food Properties, 5(1): 217-229.
Choi, M. H., Kim, G. H., and Lee, H. S. (2002). Effects of ascorbic acid retention on juice colour and pigment stability in blood orange (Citrus sinensis) juice during refrigerated storage. Food Research International, $35,753-759$

Karthikeyan, J., and S.S. Samipillai. (2010). Sugarcane in therapeutics. Journal Herbal Medicine \& Toxicology 4(1): 914.

Kidmose, U., \& Martens, H. J. (1999). Changes in texture, microstructure and nutritional quality of carrot slices during blanching and freezing. Journal of Science Food and Agriculture, 79, 1747-1753.

Krishnakumar, T. and Devadas,C.T. (2006). Microbiological changes during storage of sugarcane juice in different packaging materials. Beverage and foodworld. 33(10):82-83.

Krishnakumar, T. (2003). Studies on packaging techniques of sugarcane juice. An unpublished M.E. thesis, Faculty of Agricultural Engineering, Tamil Nadu Agricultural University, Coimbatore, India.

Mao L C., Xu Y Q, Que F (2007). Maintaining the quality of sugarcane juice with blanching and ascorbic acid. Food Chemistry 104(2): 740-745.

Margherita, R., and Giussani, E. (2003). Effect of fruit blanching on phenolics and radical scavenging activity of highbush blueberry juice. Food Research International, 36, 999-1005.

Mohd, A.N., and P. Benchamaporn. (2007). Potential of non-thermal processing for food preservation in Southeast Asian countries. International Food Research Journal 14(3): 141-152.

Ozoglu, H., and Bayindirli, A. (2002). Inhibition of enzymatic browning in cloudy apple juice with anti-browning agents. Food Control, 13, 213-221. 
Singh S., More P.K., Gaikwad K (2014). Sensory Evaluation of optimized and Stabilized Sugarcane Juice.
International Journal of Engineering Research and General Science 2(6): 637-648.

\section{How to cite this article:}

Neha Pradhan, Dilip Kumar, Priyanka Singh and Pisalkar. P. S. 2020. Sensory and Microbial Evaluation of Microwave treated Sugarcane Juice. Int.J.Curr.Microbiol.App.Sci. 9(03): 13131320. doi: https://doi.org/10.20546/ijcmas.2020.903.153 